\title{
Albanon
}

Revistë kulturore

\section{Kishat ortodokse në Elbasan sipas dëshmive të Sergio Bettinit}

Përktheu nga italishtja: Silva Belegu

\begin{abstract}
Shënim: ky material u bë i mundur falë albanologes Lucia Nadin, e cila, gjatë një vizite në universitetin e Elbasanit, solli disa kapituj të librit "Lundrimi $i$ turbullt $i$ kritikës së artit. Shkrime të pabotuara të Sergio Bettini-t (1936-1977)”, pikërisht ata kapituj ku flitej për Shqipërinë. Sipas studiueses, këto faqe, janë me interes për vendin tonë. Një kopje e këtij libri gjendet në Bibliotekën Kombëtare.
\end{abstract}

Sergio Bettini (1905-1986) është një studiues italian, i cili pati një rol kryesor në Itali në disiplinën historiko-artistike, duke vënë theksin përmes studimeve të tij, në problematikat e metodologjisë së kërkimit. Në vitet 30 të shek. XX ishte pedagog në universitetin e Padovës, në lëndët Histori e artit bizantin, Arkeologji kristiane dhe më vonë në lëndët Histori e artit mesjetar dhe estetikë, Histori dhe kritikë arti. Tepër i ndjeshëm ndaj ndryshimeve të kulturës në epokën e tij, Bettini solli në Itali tema dhe mënyra të kërkimit nga shkollat europiane më të avancuara si Shkolla e Vjenës, e strukturalizmit, e semiologjisë dhe e fenomenologiisë. Të shumtë dhe origjinalë, shkrimet e tij u botuan nga 1930 deri më 1986. Përmendim disa nga monografitë si: "Arkitektura e Shën Markos. Origjina dhe kuptimi (1946)", "Arti në fund të botës antike (1948)", "Venezia. Lindja e një qyteti (1978)". 


\section{Relacion mbi inspektimin në Shqipëri ${ }^{1}$}

Relacion mbi inspektimin e bërë me urdhër të Ministrisë së Arsimit, në Krujë, Rubik, Balldren, Kakarriq, Shkodër, Elbasan, Korçë, Voskopojë, Mborje, Boboshticë, Vithkuq.

18 prill 1940

\section{Elbasan}

Me shumë interes është kisha ortodokse e Shën Vladimirit. E restauruar kohët e fundit nga jashtë, me një arkitekture jo shumë interesante, por me objekte me vlerë në oborr dhe brenda saj. Më i rëndësishmi nga të gjithë, është ikonostasi i madh prej druri të gdhendur, që i përket shek. XVIII, i shkollës joniane. Do të ishte me interes të bëhej inventari i ikonave.

Në vija të përgjithshme shikohen këto objekte:

- lart: kryqi i madh i pikturuar, anash tij figurat e Shën Marisë dhe Shën Gjonit;

- poshtë: 14 figura shenjtësh brenda nikeve ose edikulave me arkitekturë veneciane, ndoshta e shek. XVIII, me elemente të stilit gotik, të cilat janë rimarrë nga një ikonostas më i vjetër, dhe kjo dëshmohet nga fakti se një figurë është prerë për të zënë vend në ikonostas;

- akoma më poshtë, në qendër: 9 ikona, nga të cilat 5 janë zëvendësuar me piktura moderne, të pavlera; ikonat që mbeten i përkasin shek. XVIII, ato janë: Hyrja e Krishtit në Jeruzalem, Kryqëzimi, Ngjitja në qiell, Dormitio Virginis (Fjetja e Shën Marisë);

- anash: 16 ikona të vogla, disa prej të cilave janë zëvendësuar me të reja. Të shek. XVIII janë: Lindja e Shën Marisë, Pagëzimi, Darka e fundit, Shndërrimi i Krishtit, Lindja e Krishtit, Lajmërimi, Prezantimi në Tempull;

- dyert. edhe këtu disa figura janë zëvendësuar. Mbeten të shek. XVIII: Shën Gjon Vladimiri, i datuar, dhe episode nga jeta e tij; Shën Maria Odighitria (ajo që udhëheq); Krishti dhespot; Shën Gjon Batisti me krahë.

1 Michela Agazzi, Chiara Romanelli, Lundrimi i turbullt $i$ kritikës së artit, Shkrime të pabotuara të Sergio Bettini-t (1936-1977), Marsilio 2011, f. 72-74. 


\section{Albanon}

Revistë kulturore

Ikonostasi i Shën Gjonit

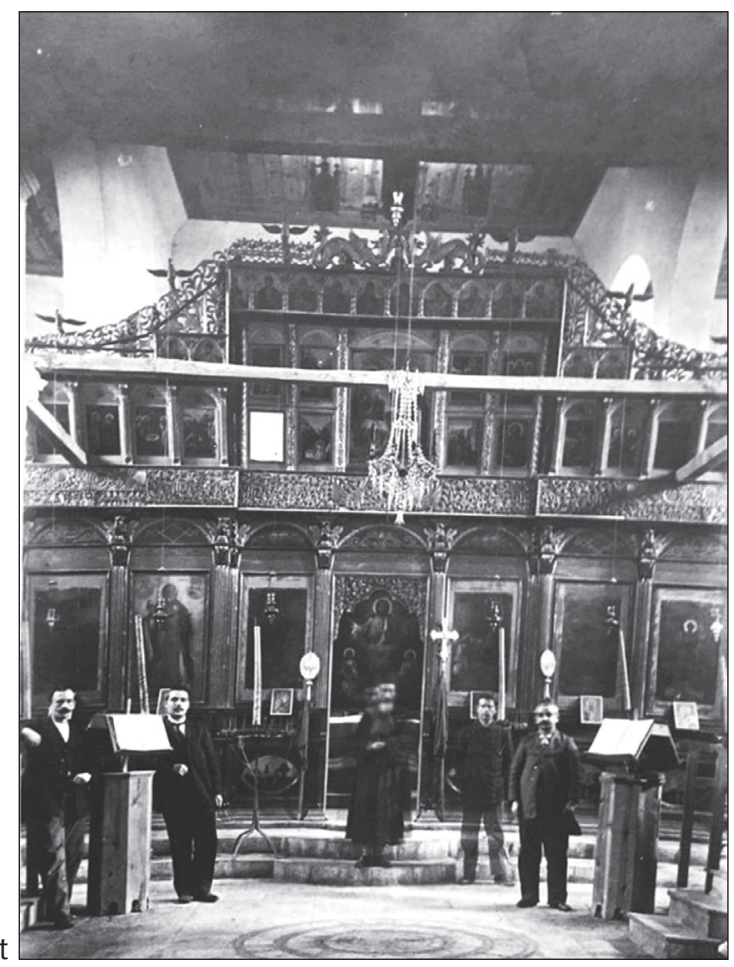

Interesante janë pikturat e apostujve në "të rrumbullakëtat” e ikonostasit dhe te dera qendrore.

- Në dianikon (vendi ku rri dhjaku në kishë): tabernakulli në të cilin ndodhet arka mortore e Shën Vladimitir, i vizatuar me tempera, me episode nga jeta e shenjtorit, i vitit 1902.

- Një ikonë e Shën Vladimirit e shek. XVII.

- $\quad$ Në bemë (sanktuar): disa ikona, por antike është vetëm ikona triptike te dollapi i murit.

- Në vendbanimin e dhjakut: fragmente të ikonostasit të parë; një nga këto me figurë shenjti.

Me interes nga këto figura, është ajo e Shën Vladimirit gjendur në ikonostas, sepse ka të shkruar datën dhe emrin e piktorit shqiptar që e ka realizuar.

1736 me dorën e Kostandinit, nëndhjakon nga Matao?

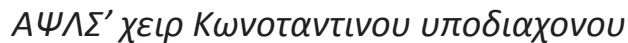

$\varepsilon \kappa M \alpha \vartheta \alpha o$ (?)

Propozime: të bëhet një inventar i plotë i të gjitha objekteve, sendeve fetare, veshjeve dhe simboleve fetare (disa prej të cilave me vlerë) të kishës dhe të 
bëhet ruajtja e tyre. Të studiohen mbetjet e skulpturave në oborr, disa prej të cilave i përkasin periudhës romako-kristiane, të katalogohen të gjitha skulpturat që ndodhen futur në mure, një prej të cilave është skulpura e famshme e Karl Topisë.

\section{Kisha e Shën Marisë}

Në këtë kishë, e cila nuk është me interes nga ana arkitektonike, pasi është restauruar së fundmi, vlerë të çmueshme ka ikonostasi, jo vetëm si i tillë, por se na jep edhe emrat dhe veprat e dy piktorëve të njohur shqiptarë, Mihail dhe djali i tij Nikolla.

Ikonostasi me siguri i përket shkollës joniane, siç janë e së njëjtës teknikë ambona (platformë nga ku kryhej predikimi i meshës) e gdhendur e gjitha në dru e në ar dhe fronti dhespotik. Pikturat në përgjithësi kanë një stil të theksuar venecian, si të Zografëve të Korfuzit apo të Zantes të shek. XVIII. Por në ikonostas ka piktura të Mihailit të Samarinës, pasi ai ka firmosur poshtë figurës së Krishtit Dhespot:

Nëpërmjet dorës së Mihailit, i panjohur nga Samarina

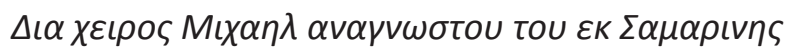

Është një piktor që paraqet interes, ka mundësi të ketë jetuar në shek. XVIII, ka një stil të ngjashëm me piktorët greko-veneciane Zen, të cilët punuan në ishujt e Jonit. Me shumë mundësi ai është autori i afreskeve, ose thënë më mirë i vizatimeve me tempera në muret e kishës; Pantokrator-i (i gjithëpushteshmi) me evangjelistët në kupolën e kishës, të tjera që ndodhen në Bemë. Mihaili duhej të kishte si bashkëpunëtor të birin Nikollën, të cilit i njohim emrin, sepse ka firmosur poshtë ikonave të Shën Kostandinit dhe Shën Helenës:

Me dorën e Nikollës, biri i Mihail Zografit nga Kronstavi 1849

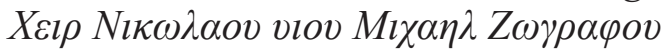

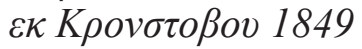

Edhe kjo datë konfirmon që babai i Nikollës duhej të kishte jetuar e punuar rreth fundit të shek. XVIII.

Në kishë ka ikona të tjera, me interes të ndryshëm, por të gjitha për t’u inventarizuar e për t’u ruajtur: gjë që propozohet këtu. 